Advisory Council on Scientific Policy. The Government had in mind the scope such a project would provide for co-operation with Commonwealth countries, but such discussions could most profitably proceed when the scale and nature of any British effort had been decided. Mr. Jones agreed that the danger of losing our youngest and ablest scientists to the United States in the absence of occasional opportunities for such research, even if it involved using equipment originally designed for a specific military purpose, was an important consideration. Mr. Jones promised that a statement would be made quite soon.

\section{Commercial Manufacture of Nuclear Fuel Elements}

IN reply to a question regarding the circumstances in which a private company was permitted to manufacture nuclear fuel elements, and the security reasons for the refusal of the Parliamentary Secretary to the Ministry of Power to reveal, on April 21, which organization other than the Atomic Energy Authority was preparing to make such elements, the Prime Minister stated that the Parliamentary Secretary was unwilling to go into greater detail until he had been able to refer to the defence authorities as to whether any question of security arose. Mr. Macmillan now saw no objection to stating that it was the intention that Rolls-Royce, Ltd., should manufacture fuel elements for nuclear submarine machinery. The material would be supplied by and would remain the property of the Admiralty. At present all nuclear fuel was manufactured by the Authority, but it was likely that in future elements would be manufactured in some of the processes of industry. The Nuclear Installations (Licensing and Insurance) Bill at present under consideration in Committee ought to provide for this, and all such material would either be the property of the Authority or manufactured only under licence and control, for which the Bill set up a proper system. Except for a certain amount of processing, Mr. Macmillan thought that for many years all nuclear fuel would be supplied either by the Atomic Energy Authority or, for defence purposes, by the Defence Departments.

\section{The Royal College of Surgeons of England}

THE recent intense activity in the Royal College of Surgeons, which has aroused considerable interest among both the professional and lay public, is not in fact a recent development. Before the Second World War the scientific work undertaken by the College had been extended by adding a Department of Physiology to the old-established Departments of Anatomy and Pathology in Lincoln's Inn Fields, London, and by establishing a centre for experimental surgical research, the Buckston-Browne Farm, at a site adjacent to Darwin's old home at Downe. But since the War, the programme of research and education has gained fresh impetus from the need for reconstruction after the grievous damage which the College suffered in 1941, and from the needs of postgraduates seeking higher qualifications in surgery, dental surgery and anæsthetics. When planning the rebuilding of the College, the Council therefore resolved that laboratories should take the place of some of the destroyed museums, and that Departments of Pharmacology and Biochemistry should be established to provide a complete syllabus of postgraduate education in the basic medical sciences which would be available not only to young surgeons but also to all postgraduates studying for any of the higher diplomas for which these subjects are required. Recognizing that teachers must be provided with accommodation and equipment for research if a high academic standard is to be maintained, the College included in its building programme a very considerable expansion of the floor area for laboratories as well as a corresponding extension of the Library. These plans were designed to discharge what the Council regarded as its plain duty to postgraduates, and to meet its ancient obligation to promote the science as well as the art of surgery.

In making these decisions the Council had to face the problem of finding the money to pay for new buildings and to maintain the new research departments. Fees from students and the welcome contribution from the University of London through the British Postgraduate Medical Federation provided only a small fraction of the sums required, which now stand at $£ 350,000$ to complete the buildings and an annual $£ 150,000$ for the salaries of teachers, research workers and technicians and for laboratory maintenance. The College exerts a far-reaching influence upon the National Health Service, but is not a hospital and therefore is not eligible for a direct grant from the Government. The Fellows have contributed handsomely to College funds, thus showing their confidence in the policy of the Council ; but in order to raise these large sums of money an appeal to the public for funds has recently been launched. Already most generous support has been forthcoming from the friends of the College in industry, commerce and in the world of finance, whose example should be followed by many others who have the understanding and the vision to see that by supporting surgical research and education they are promoting the best interests of themselves, their families and their dependants.

\section{Italian Nuclear Research Centre at Ispra}

The President of Italy, Signor Gronchi, formally opened the Italian Nuclear Research Centre at Ispra on April 13 before a distinguished gathering of about a thousand people. Ispra is about a mile from the extreme south of Lake Maggiore and about 35 miles from Milan, with which it is connected by autostrada. The centre is set in a beautiful district and occupies 340 acres of part grassland and part woods. Ultimately it should have a working population of around a thousand. Work began on the site in the late summer of 1957 and later in the year an organization headed by Prof. Carlo Salvetti was set up in Milan to prepare for the move to Ispra. About three weeks before the official opening of the centre, Ispra-1, a 5-MW. heavy water-moderated research reactor, fueled by 20 per cent enriched uranium with a fast neutron flux of $1.1 \times 10^{14} \mathrm{n} / \mathrm{cm} .^{2} \mathrm{sec}$. and a thermal neutron flux of $8 \times 10^{13} \mathrm{n} / \mathrm{cm} .^{2}$ sec., went critical. This reactor is a modification of the CP-5 reactor at the Argonne National Laboratory which operates at $1 \mathrm{MW}$. The moderator and fuel for the reactor were imported from the United States, as were some of the most important reactor components, so as to speed up the construction of the reactor. At the opening ceremony the United States Atomic Energy Commissioner, Mr. Floberg, made a speech in Italian and handed a cheque for 350,000 dollars to President Gronchi as the American contribution to the cost of the reactor.

Ispra-1 is enclosed in a gas-tight metal cylinder, $79 \mathrm{ft}$. high, which is kept at a negative pressure as a safety measure. Several laboratories are grouped 